\title{
Possible Future Climate Change Impacts on the Hydrological Drought Events in the Weihe River Basin, China
}

\author{
Fei Yuan, ${ }^{1}$ Mingwei Ma, ${ }^{1}$ Liliang Ren, ${ }^{1}$ Hongren Shen, ${ }^{1}$ Yue $\mathrm{Li}^{2}{ }^{2}$ Shanhu Jiang, \\ Xiaoli Yang, ${ }^{1}$ Chongxu Zhao, ${ }^{1}$ and Hao Kong ${ }^{1}$ \\ ${ }^{1}$ State Key Laboratory of Hydrology-Water Resources and Hydraulic Engineering, College of Hydrology and Water Resources, \\ Hohai University, 1 Xikang Road, Nanjing 210098, China \\ ${ }^{2}$ Patent Examination Cooperation Center of the Patent Office, SIPO, Henan, Zhengzhou 450000, China
}

Correspondence should be addressed to Fei Yuan; fyuan@hhu.edu.cn

Received 29 May 2015; Revised 23 September 2015; Accepted 28 September 2015

Academic Editor: Maurits W. Ertsen

Copyright (C) 2016 Fei Yuan et al. This is an open access article distributed under the Creative Commons Attribution License, which permits unrestricted use, distribution, and reproduction in any medium, provided the original work is properly cited.

\begin{abstract}
Quantitative evaluation of future climate change impacts on hydrological drought characteristics is one of important measures for implementing sustainable water resources management and effective disaster mitigation in drought-prone regions under the changing environment. In this study, a modeling system for projecting the potential future climate change impacts on hydrological droughts in the Weihe River basin (WRB) in North China is presented. This system consists of a large-scale hydrological model driven by climate outputs from three climate models (CMs) for future streamflow projections, a probabilistic model for univariate drought assessment, and a copula-based bivariate model for joint drought frequency analysis under historical and future climates. With the observed historical climate data as the inputs, the Variable Infiltration Capacity hydrological model projects an overall runoff reduction in the WRB under the Intergovernmental Panel on Climate Change A1B scenario. The univariate drought assessment found that although fewer hydrological drought events would occur under AlB scenario, drought duration and severity tend to increase remarkably. Moreover, the bivariate drought assessment reveals that future droughts in the same return period as the baseline droughts would become more serious. With these trends in the future, the hydrological drought situation in the WRB would be further deteriorated.
\end{abstract}

\section{Introduction}

Nowadays our societies are in much more urgent need of water resources, particularly in the drought-prone territories in China and in other parts of the world. In such regions, increasingly frequent droughts are becoming a main threat to local socioeconomic and ecoenvironment systems [1]. Even in humid areas of South China, where droughts used to be less frequent, several long-lasting, severe, and widespread drought events were witnessed in the 2000s and 2010s, causing serious water shortage problems and sharp damage (e.g., the severe 2010 drought in Southwest China) [2, 3]. In Northern China, such as the Yellow River basin (YRB), drought situations can be even worse because of the semiarid to arid climatology and limited atmospheric water sources [4]. Therefore, the focus of this study is on the largest tributary of YRB, that is, the drought-prone Weihe River basin (WRB), where large human population, extensive areas of rainfall and/or irrigation-fed agriculture, rapid industrial and economic developments, and vulnerable ecological and environmental systems meet and conflict between water supply and demand. Several studies have shown that the WRB suffered from disastrous drought periods in history (e.g., 1962, 1972, 1987, and 1990s) and the drought trends of this region tend to deteriorate as well $[5,6]$. For mitigation purposes, the water volume stored in river systems (e.g., streamflow) is often analyzed to define hydrological droughts. Based on the theory of runs, drought variables (e.g., duration and severity) can also be extracted to investigate their univariate and multivariate probabilistic properties and frequency analysis $[7,8]$. However, the hydrological drought characteristics of the YRB have not yet been systematically investigated and 
reported. On the other hand, although [9-12] studied the variations of runoff/streamflow and its responses to climate change in the WRB, it is still unclear how potential climate change (especially the global warming) impacts future extreme hydrological drought events in this region.

Therefore this study aims to propose an effective framework to evaluate historical (1961-1990 as baseline period) drought conditions and to project future (2011-2040 as climate change period) hydrological drought properties in the WRB. Specifically, the new framework consists of four components: (1) the Variable Infiltration Capacity (VIC) hydrologic model driven by climate outputs from three climate models (CMs) for future streamflow projections, (2) a drought variable identification model for drought severity and duration based on the theory of runs, (3) a probabilistic model for univariate drought assessment and frequency analysis (duration and severity) under historical and future climates, and (4) a copula-based model for bivariate drought assessment and joint frequency analysis. This framework provides quantitative evaluation of climate change impacts on hydrological drought characteristics in the WRB.

Though [13] applied similar approaches to a river basin in USA, they adopted the Thornthwaite water balance model (a simple conceptual hydrologic model) to simulate future runoff and used the standardized streamflow index to define hydrological droughts. In this study, the authors employed the physically based VIC distributed hydrological model for historical streamflow simulations and future runoff projections. In addition, streamflow at certain levels was directly used as truncation thresholds to define hydrological drought duration and severity. This approach makes it more convenient to compare historical and future drought properties and to interpret climate change impacts on drought characteristics. Moreover, the adopted CMs and univariate and copula-based multivariate models are also quite different from those of [13]. In general, such a study using multimodels (climatic, hydrological, and multivariate probabilistic) has not been documented in the WRB. This work is expected to fill the research gap of future climate change impacts on hydrological droughts and to provide reliable data support for upgrading water resources management and adaptation strategies in response to changing environment in this region.

\section{Study Area}

The Weihe River is the longest tributary of the Yellow River in North China, with a drainage area of $1.348 \times 10^{5} \mathrm{~km}^{2}$ (Figure 1). The river basin is dominated by continental monsoon climate and characterized as semiarid region. The annual mean temperature ranges between $9.3^{\circ} \mathrm{C}$ and $14.4^{\circ} \mathrm{C}$. The mean annual precipitation is $511.3 \sim 659.1 \mathrm{~mm}$, with a distinct increase from northwest to southeast. Precipitation mainly occurs from June to November, which accounts for $70.8 \sim 74.2 \%$ of annual precipitation. Snow generally occurs in winter in the entire basin. The spatiotemporal distribution of runoff is similar to precipitation, with basin-averaged mean annual runoff depth being less than $100 \mathrm{~mm}$. The basin is prone to droughts. Agricultural losses due to local drought disasters occupy over $50 \%$ of the total losses. Recent climate

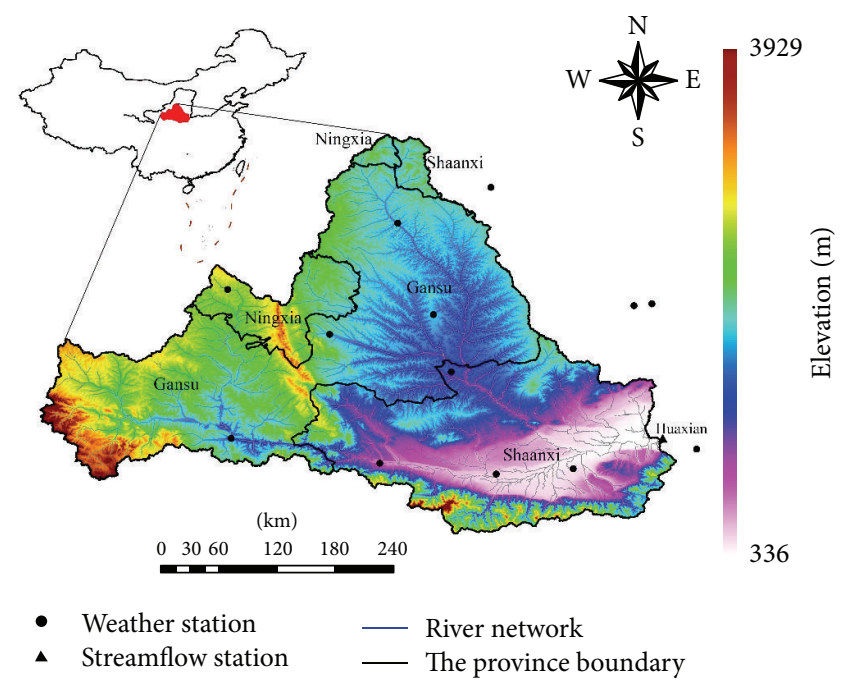

FigURE 1: Map of study area.

change has deteriorated the water shortage situation in the $\mathrm{WRB}$ and resulted in more severe drought events. Thus it is necessary to assess the possible climate change impacts on regional hydrological drought events. In this study, the area controlled by Huaxian streamflow station (upstream area of $1.065 \times 10^{5} \mathrm{~km}^{2}$, Figure 1) was selected as the study region.

\section{Data and Methodology}

3.1. Data. Historical meteorological data of thirteen weather stations within or nearby the basin (Figure 1) were obtained from China Meteorological Administration. These data include daily records of maximum and minimum air temperature and precipitation during the period of 1961-2012. The whole basin was divided into 213 grid cells at a $0.25^{\circ}$ resolution. All the station-based daily precipitation and air temperature data were interpolated to each $0.25^{\circ}$ grid cell by the nearest neighbor method. Topographical effects were not considered in precipitation interpolation, while nearsurface air temperature was assumed to decrease by $0.65^{\circ} \mathrm{C}$ per altitude rise of $100 \mathrm{~m}$.

China's land-use/cover data sets with 5 or $10 \mathrm{yr}$ intervals between 1980 and 2010 [14] were used to analyze the land-use change in the study area. It shows that cropland, the dominant land-use type in the region of the middle and lower reaches, has a downward trend since late 1980s. The cover ratio of woodland in the upstream region drops sharply since late 1980s and approximately trends to be stable after the 1990s. The built-up area increased notably since 1980, implying the rapid urbanization in this region. The coverage of water bodies, which refer to the lakes, reservoirs, ponds, and other water retaining projects for the irrigations, has also shown an upward trend. Furthermore, the Pettitt jump test for the annual runoff depth time series from 1961 to 2012 at Huaxian station indicates that the year 1990 is the abrupt change point in annual runoff with a significant decrease trend since 1990. Meanwhile, the consistency test with the double mass curve of the cumulative annual areal mean precipitation and observed 
runoff depth shows that runoff coefficient tends to decrease since 1990 as well. Therefore, considering the change patterns of land-use, precipitation and runoff, the period of 1961-1990 was defined as the baseline period for hydrological drought projections in this study.

Climate data sets from three climate models (CMs) were adopted in this study. They are Australian Commonwealth Scientific and Research Organization (CSIRO) Mk 3.5 Global Climate Model (GCM), German Max Planck Institute for Meteorology (MPI) ECHAM 5 GCM, and Hadley Centre's Providing Regional Climates for Impacts Studies (PRECIS) regional climate model (RCM). The CSIRO and MPI GCMs run at a spatial resolution of $1.875^{\circ} \times 1.875^{\circ}$ and $2.0^{\circ} \times 2.0^{\circ}$, respectively. The output of these two GCMs was statistically downscaled to a $50 \mathrm{~km} \times 50 \mathrm{~km}$ resolution by the bilinear interpolation and quantile-mapping methods. The PRECIS RCM dynamically downscales the HadAM3H GCM data from the $1.25^{\circ} \times 1.875^{\circ}$ resolution to $50 \mathrm{~km} \times 50 \mathrm{~km}$. The three CM data sets are composed of the simulated daily maximum and minimum air temperature and precipitation in the baseline period of 1961-1990 and in the years of 20112040 under A1B scenario of the Intergovernmental Panel on Climate Change (IPCC) Special Report on Emission Scenarios (SRES) [15]. The IPCC-SRES A1B shows rapid economic growth, especially in developing nations, with a balance across all energy sources for economic development, and it has been adopted as the most commonly used emission scenario for climate change studies in China [16, 17]. Furthermore, linear interpolation was performed to transform the three downscaled CM data sets $(50 \mathrm{~km} \times 50 \mathrm{~km})$ to a $0.25^{\circ}$ resolution. In this study, the observed historical climate data set in 1961-1990 was directly employed as the baseline climatology. To bias-correct the CM data sets, the deltachange method was used, which superimposes the mean monthly anomalies between the CM-simulated baseline and A1B climate data on the observed historical meteorology to represent future climate. In this way, three future climate data sets were finally constructed for three future scenarios, namely, A1B PRECIS, A1B CSIRO, and A1B MPI.

3.2. Variable Infiltration Capacity Hydrological Model. The Variable Infiltration Capacity (VIC) model $[18,19]$ is a stateof-the-art physically based distributed hydrological model. It simulates radiative fluxes, turbulent fluxes of momentum, sensible heat, unsaturated liquid water transport, saturated gravitational drainage, surface runoff, bottom drainage evapotranspiration, freezing, and thawing of soil ice at each land grid cell. Additionally, a conceptual streamflow routing model is included to route the computed runoff depth at each grid cell to the watershed outlets. The routing model simulates two processes: (1) runoff concentration on the outflow of each grid cell is represented by the linear reservoir method; (2) the routing effect of channel system connecting grid cells is represented by the Muskingum routing algorithm [20].

In this study, the vegetation and soil parameters of the VIC model were spatially estimated a priori according to vegetation and soil texture classes at each grid cell. For each type of vegetation, the vegetation parameters, such as architectural resistance $r_{a}(\mathrm{~s} / \mathrm{m})$, albedo $\alpha$, minimum stomata resistance $r_{\text {smin }}(\mathrm{s} / \mathrm{m})$, leaf-area index LAI, roughness length $z_{0}(\mathrm{~m})$, and zero-plane displacement $d_{0}(\mathrm{~m})$, were derived on the basis of the vegetation parameter information from Land Data Assimilation Systems (LDAS, http://das.gsfc.nasa.gov/ gldas/GLDASmapveg.php). The individual soil parameters used in VIC, such as porosity $\theta_{s}$, saturated soil potential $\psi_{s}$, saturated hydraulic conductivity $K_{s}$, and bulk density BD, were derived according to the work of $[21,22]$. In addition, two insensitive hydrologic parameters of VIC were estimated a priori according to the work of [23]. These parameters are the following: (1) $D_{\text {soil }}$ : soil depth of each soil layer (three layers in this study) is set as $0.1 \mathrm{~m}, 0.5 \mathrm{~m}$, and $1.5 \mathrm{~m}$, respectively; (2) $W_{s}$ : the fraction of the maximum soil moisture (of the lowest soil layer) where nonlinear baseflow occurs is defined as 0.99. Other sensitive VIC hydrologic parameters (such as $\mathrm{Ds}_{\max }$, maximum baseflow that can occur from the lowest soil layer; Ds, fraction of $\mathrm{Ds}_{\max }$ where nonlinear baseflow begins; and $b_{\text {inf }}$, coefficient defining the shape of the Variable Infiltration Capacity curve) and runoff routing parameters were calibrated by fitting the daily calculated streamflow time series against the observed records. These sensitive parameters are calibrated within the predefined rational physical value ranges by the Shuffled Complex Evolution (SCE-UA) automatic optimization method [24], with the logtransformed Nash-Sutcliffe model efficiency coefficient as the objective function.

In this study, the gridded baseline and three future climate data sets were, respectively, used to drive the VIC model for daily streamflow simulations and projections at Huaxian station. Subsequently, the monthly simulated streamflow time series accumulated from the daily time series were analyzed to assess hydrological drought properties using univariate and bivariate drought distributions.

3.3. Univariate Drought Distribution Model. The VIC-simulated monthly streamflow time series were used to identify the hydrological drought events under the baseline (19611990) and three A1B (2011-2040) scenarios by the theory of runs. Following [25], three truncation levels of streamflow, $Q_{0}, Q_{1}$, and $Q_{2}\left(Q_{0}>Q_{1}>Q_{2}\right)$, were used to identify the hydrological drought events and relevant drought characteristics (Figure 2). As shown in Figure 2, four possible hydrological drought events (indicated as $a, b, c$, and $d$ ) are preliminarily identified during the period when the simulated monthly streamflow is below the truncation streamflow $Q_{1}$. For the events with one-month duration ( $a$ and $d$ in Figure 2), only the event $a$ is finally identified to be a drought event as its monthly streamflow is below the truncation streamflow $Q_{2}$, but the event $d$ is rejected to be a hydrological drought with its monthly streamflow being above $Q_{2}$. For the two sequential events with the interval time of one month $(b$ and $c$ in Figure 2), the two events $b$ and $c$ are combined to be one drought event on the condition that the monthly streamflow at the interval is below the truncation streamflow $Q_{0}$; otherwise the events $b$ and $c$ are considered to be two independent drought events. For each identified drought event, the corresponding drought severity is the cumulative deviation below the truncation streamflow $Q_{1}$ during 


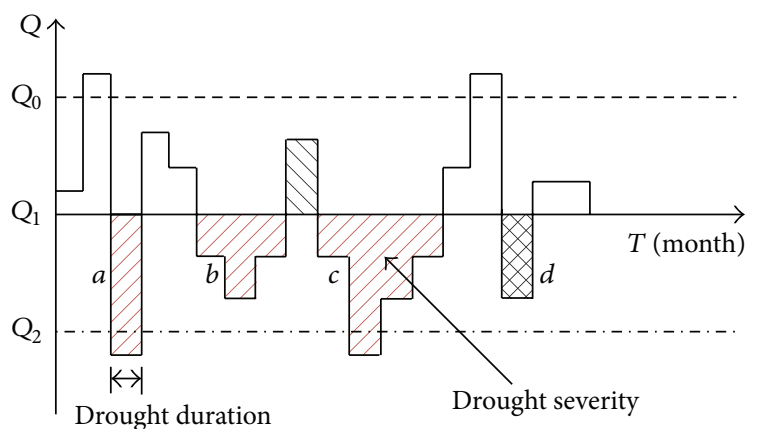

FIGURE 2: Diagram of drought identification using the theory of runs.

the drought duration (Figure 2). According to Standard for Information and Hydrological Forecasting of China [26], the truncation streamflow $Q_{0}$ in this study was defined to be the monthly mean of the simulated streamflow time series from 1961 to 1990 at Huaxian station, and $Q_{1}$ and $Q_{2}$ were assumed to be $10 \%$ and $20 \%$ below $Q_{0}$, respectively.

Using the drought identification scheme (Figure 2), the drought variables of duration and severity were derived for each drought event under the baseline and A1B PRECIS, A1B CSIRO, and A1B MPI scenarios. For the analysis using univariate drought distributions, the exponential and Weibull distributions were, respectively, used to fit the drought duration and severity samples under the baseline and three future scenarios, and the maximum likelihood method was used to estimate the distribution parameters. Additionally, the univariate return periods of drought events regarding only one variable (drought duration or severity) were also derived under the baseline and three A1B scenarios, which are shown as follows:

$$
\begin{aligned}
& T_{D}=\frac{E(L)}{1-F_{D}(d)}, \\
& T_{S}=\frac{E(L)}{1-F_{S}(s)},
\end{aligned}
$$

where $D$ and $S$ denote drought duration and severity, respectively; $T_{D}$ and $T_{S}$ represent the univariate return period for droughts with $D \geq d$ and $S \geqslant s$, respectively; $E(L)$ is the mean interarrival time of droughts; $F_{D}(d)$ and $F_{S}(s)$ are the cumulative probability distribution functions of drought duration and severity, respectively.

3.4. Bivariate Drought Distribution Model. In reality, drought duration and severity are often significantly correlated. Therefore, the relevance between drought duration and severity should be carefully taken into account when using both drought variables for drought frequency analysis. Copulas are functions that link univariate distribution functions to form multivariate distributions [27, 28]. They are useful tools to effectively reflect the correlation features among multiple drought variables. With simple forms and good accuracies, the Archimedean copulas have been widely applied in drought studies $[7,13]$. In this study, four Archimedean copulas were used to establish bivariate drought distribution that describes the joint probabilities of drought duration and severity. They are Gumbel-Hougaard, Clayton, Frank, and Ali-Mikhail-Haq copulas. Given the univariate distributions of drought duration and severity $\left(F_{D}(d)\right.$ and $\left.F_{S}(s)\right)$, the joint distributions for drought duration and drought severity using the four Archimedean copulas can be, respectively, formulated as follows:

$$
\begin{aligned}
& F_{D, S}(d, s)=\exp \left\{-\left[\left(-\ln F_{D}(d)\right)^{\theta}+\left(-\ln F_{S}(s)\right)^{\theta}\right]^{1 / \theta}\right\}, \\
& F_{D, S}(d, s)=\left(F_{D}(d)^{-\theta}+F_{S}(s)^{-\theta}-1\right)^{-1 / \theta}, \\
& F_{D, S}(d, s)=-\frac{1}{\theta} \ln \left[1+\frac{\left(e^{-\theta F_{D}(d)}-1\right)\left(e^{-\theta F_{S}(s)}-1\right)}{\left(e^{-\theta}-1\right)}\right], \\
& F_{D, S}(d, s) \\
& =\frac{(1-\theta) F_{D}(d) F_{S}(s)}{\left\{1-\theta\left[1-F_{D}(d)\right]\right\}\left\{1-\theta\left[1-F_{D}(d)\right]\right\}-\theta F_{D}(d) F_{S}(s)},
\end{aligned}
$$

where $F_{D, S}(d, s)$ is the joint probability distribution of drought duration and severity; $\theta$ is the copula parameter representing the degree of association between $F_{D}(d)$ and $F_{S}(s)$.

With the joint probability distribution of drought duration and severity, conditional probability can also be calculated. Given drought duration exceeding a certain threshold $d$, the probability of drought severity is defined as

$$
\begin{aligned}
P(S \leq s \mid D \geq d) & =\frac{P(S \leqslant s, D \geqslant d)}{P(D \geqslant d)} \\
& =\frac{F_{S}(s)-F_{\mathrm{DS}}(d, s)}{1-F_{D}(d)} .
\end{aligned}
$$

In addition, two types of bivariate return periods, defined as $T_{\mathrm{DS}}^{\mathrm{AND}}$ and $T_{\mathrm{DS}}^{\mathrm{OR}}$, were calculated. $T_{\mathrm{DS}}^{\mathrm{AND}}$ represents the return period when both drought duration and severity exceed their specific values:

$$
\begin{aligned}
T_{\mathrm{DS}}^{\mathrm{AND}} & =\frac{E(L)}{P(D \geqslant d, S \geqslant s)} \\
& =\frac{E(L)}{1-F_{D}(d)-F_{S}(s)+F_{\mathrm{DS}}(d, s)},
\end{aligned}
$$

and $T_{\mathrm{DS}}^{\mathrm{OR}}$ denotes the return period when drought duration is higher than a specific value or drought severity exceeds another specific value:

$$
T_{\mathrm{DS}}^{\mathrm{OR}}=\frac{E(L)}{P(D \geqslant d \text { or } S \geqslant s)}=\frac{E(L)}{1-F_{\mathrm{DS}}(d, s)} .
$$

\section{Results}

4.1. Historical Hydrological Streamflow Simulations. Historical daily streamflow in the baseline period (1961-1990) at Huaxian station was simulated using the VIC model fed with the observed precipitation and air temperature data (baseline climate data set). The VIC model was calibrated by fitting the 
TABLE 1: Performance of historical monthly streamflow simulations at Huaxian station.

\begin{tabular}{lccc}
\hline Periods & Nash-Sutcliffe coefficient & Log-transformed Nash-Sutcliffe coefficient & Bias (\%) \\
\hline Calibration (1961-1980) & 0.829 & 0.715 & 3.1 \\
Validation (1981-1990) & 0.902 & 0.809 & 7.3 \\
\hline
\end{tabular}

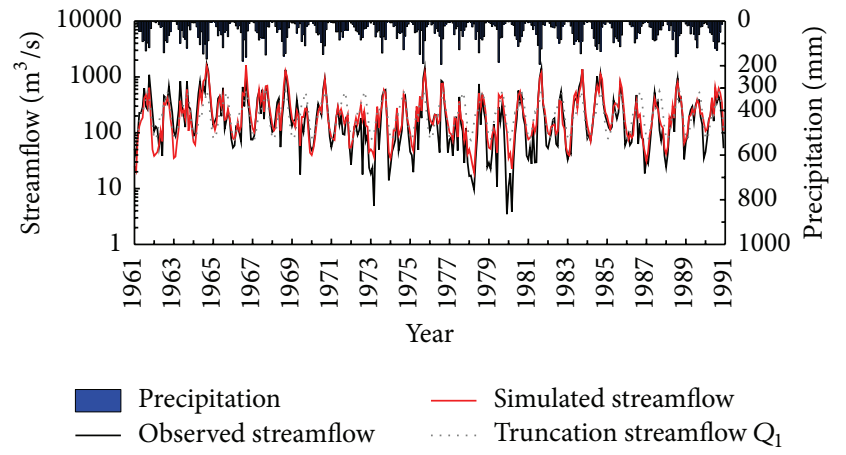

Figure 3: Observed and simulated monthly hydrographs at Huaxian station in the years 1961-1990.

calculated daily streamflow against the observed streamflow at Huaxian station with the aid of the Shuffled Complex Evolution (SCE-UA) automatic optimization method. Table 1 and Figure 3 show that the VIC model can provide reasonable streamflow simulations in calibration and validation periods in terms of the log-transformed Nash-Sutcliffe model efficiency coefficient and the relative error (bias) between the simulated and the observed total runoff.

4.2. Validation of Historical Hydrological Droughts. According to the theory of runs, the simulated monthly streamflow time series at Huaxian station in the baseline period (19611990) were used to derive the historical hydrological drought characteristics for univariate and bivariate drought analysis. For univariate drought analysis, the exponential and Weibull distributions were adopted to fit the identified historical drought duration and severity samples, respectively. The twosample Kolmogorov-Smirnov (K-S) test was used to test whether the selected theoretical distributions are able to effectively represent the distributions of drought duration and severity, respectively. Figure 4(a) shows that the Z-score of the K-S test statistics $\left(Z_{\mathrm{K}-\mathrm{S}}\right)$ is much lower than the critical Z-score $\left(Z_{\text {cri }}\right)$ at a $5 \%$ significance level, indicating that the historical drought duration and severity samples are in a good agreement with the exponential and Weibull distributions, respectively. To derive the joint distribution for the historical drought severity and duration, four copula functions were adopted. The root mean square error (RMSE) was used to calculate the biases between the empirical and theoretical joint distributions. Table 2 shows that the Clayton copula has the lowest RMSE among all the four copulas, and the Pearson correlation coefficient between the empirical probability and the Clayton-based theoretical joint probability is 0.991 in the baseline period (Figure 5(a)), implying that the Clayton copula is able to fit the joint duration-severity probability
TABLE 2: RMSE of fitting four copula functions to joint distributions for drought severity and duration under baseline and three A1B scenarios.

\begin{tabular}{lcccc}
\hline \multirow{2}{*}{ Scenarios } & \multicolumn{5}{c}{ RMSE } \\
& Gumbel-Hougaard & Clayton & Frank & Ali-Mikhail-Haq \\
\hline Baseline & 0.2334 & $\mathbf{0 . 0 4 6 5}$ & 0.1655 & 0.8975 \\
A1B PRECIS & 0.2368 & $\mathbf{0 . 0 5 3 6}$ & 0.1746 & 0.2117 \\
A1B CSIRO & 0.2313 & $\mathbf{0 . 0 6 8 1}$ & 0.1682 & 0.1569 \\
A1B MPI & 0.2309 & $\mathbf{0 . 0 7 0 3}$ & 0.1425 & 1.6671 \\
\hline
\end{tabular}

distribution for the historical drought events with very high accuracy.

Given that the records of historical hydrological droughts were not available in the WRB, the findings of [29] were used to validate the feasibility of the univariate and bivariate probabilistic models in identifying historical hydrological droughts. Reference [29] made survey of statistics on the historical droughts in provincial administrative regions in China in the years 1949-2000 and defined drought situations regarding the annual reduction rate of grain yield. For instance, a severe drought year refers to the time period when local annual grain yield reduces by $5 \sim 7 \%$, and an extreme drought year with a reduction rate of over $7 \%$. Figure 1 indicates that Shaanxi and Gansu provinces occupy the WRB predominantly. Therefore, the annual records with severe droughts or extreme droughts in Shaanxi or Gansu were used for historical hydrological drought validation. As shown in Table 3 , severe droughts or/and extreme severe droughts occurred in Shaanxi or/and Gansu for twelve years in the baseline period (1961-1990), and the top ten most severe drought events in the baseline period (1961-1990) identified by the univariate and bivariate drought models were compared with the severe and extreme drought records in Shaanxi and Gansu. Table 3 shows that the univariate and bivariate drought models in this study are able to effectively identify most historical drought years with severe and extreme drought conditions in Shaanxi and Gansu provinces. Although the historical agricultural drought records from [29] are mostly consistent with the modeling results, it is still necessary to collect the hydrological drought records for model validation in future studies so as to improve the credibility of the drought models.

4.3. Projected Changes in Hydrometeorological Variables. The baseline mean monthly air temperature and precipitation were compared with the corresponding projected $\mathrm{AlB}$ values (Figures 6(a) and 6(b)). It is found that the three CMs project a considerable increase in air temperature under $\mathrm{A} 1 \mathrm{~B}$ throughout the whole year, with a rise of $1.0 \sim 2.0^{\circ} \mathrm{C}$ 

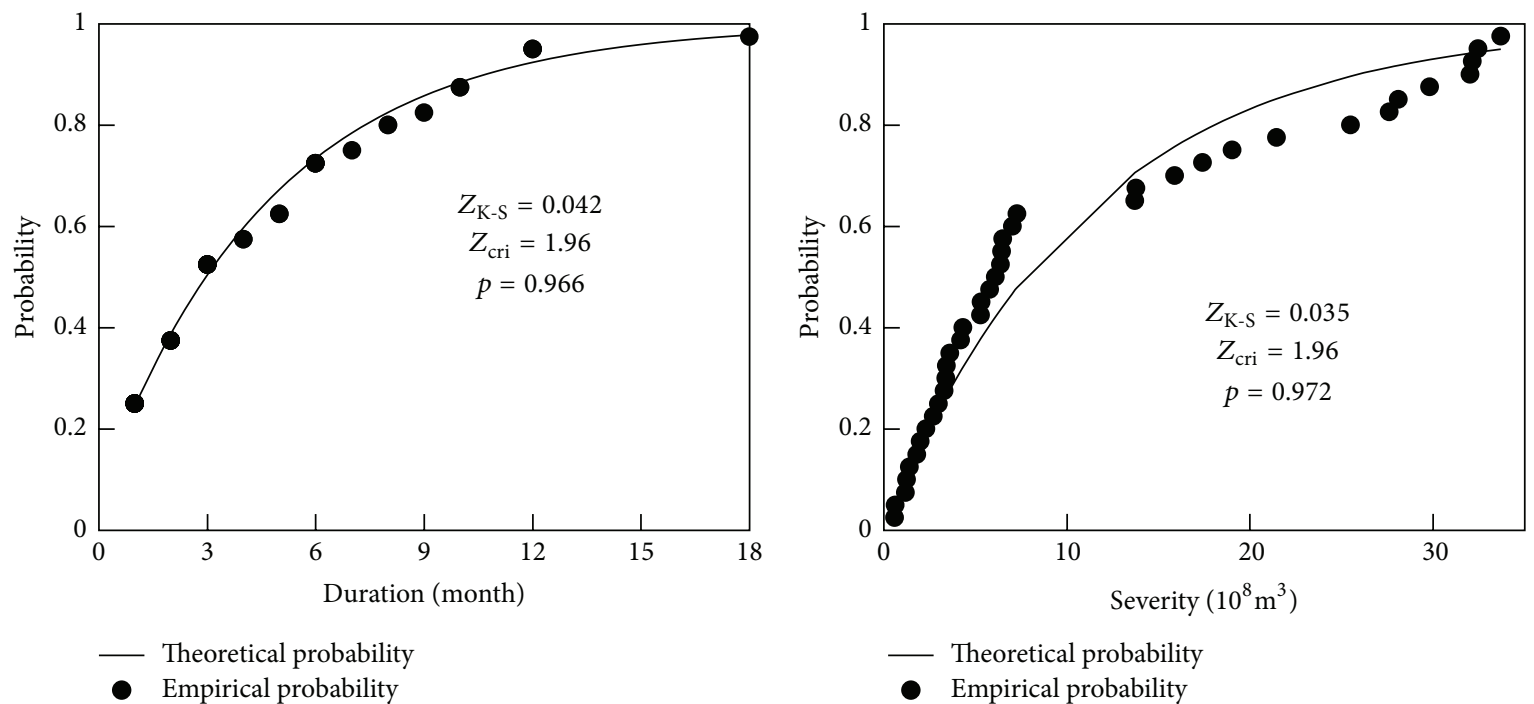

(a) Baseline
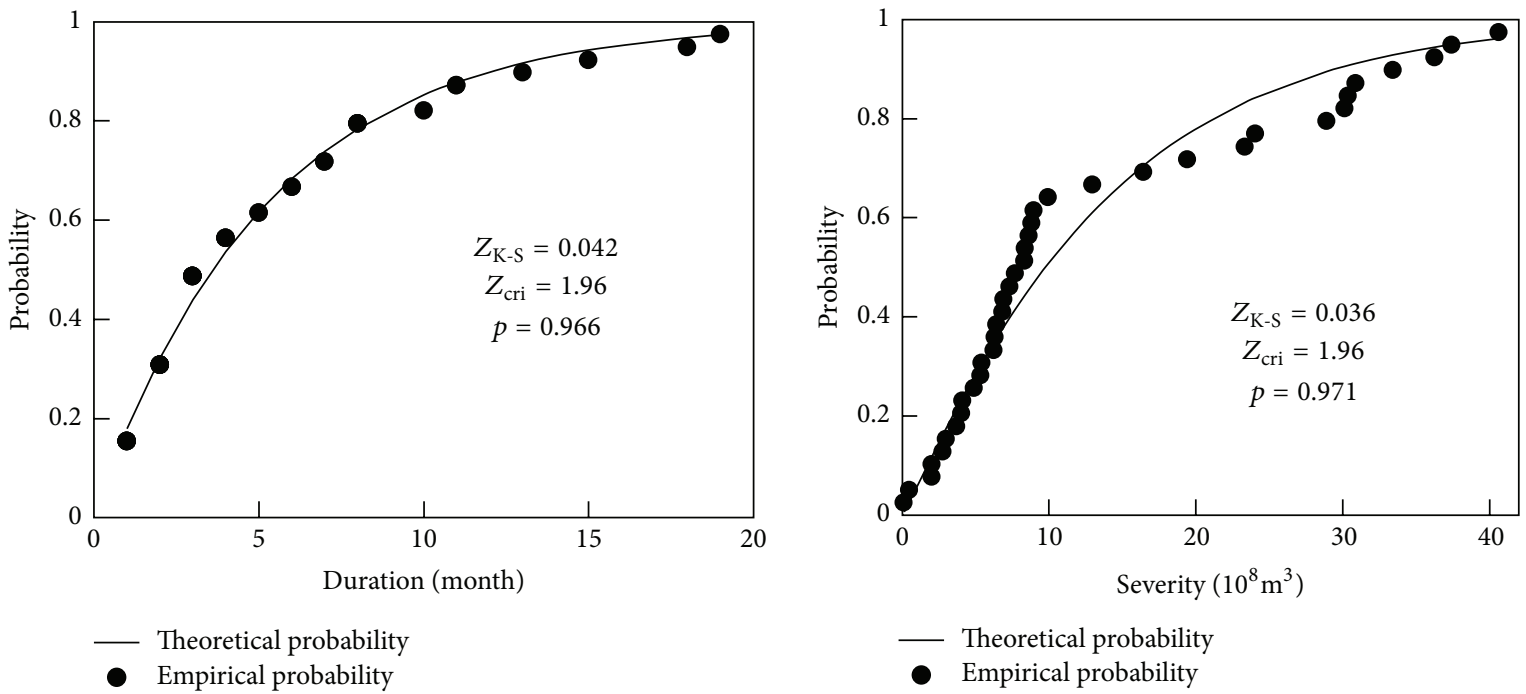

(b) A1B PRECIS
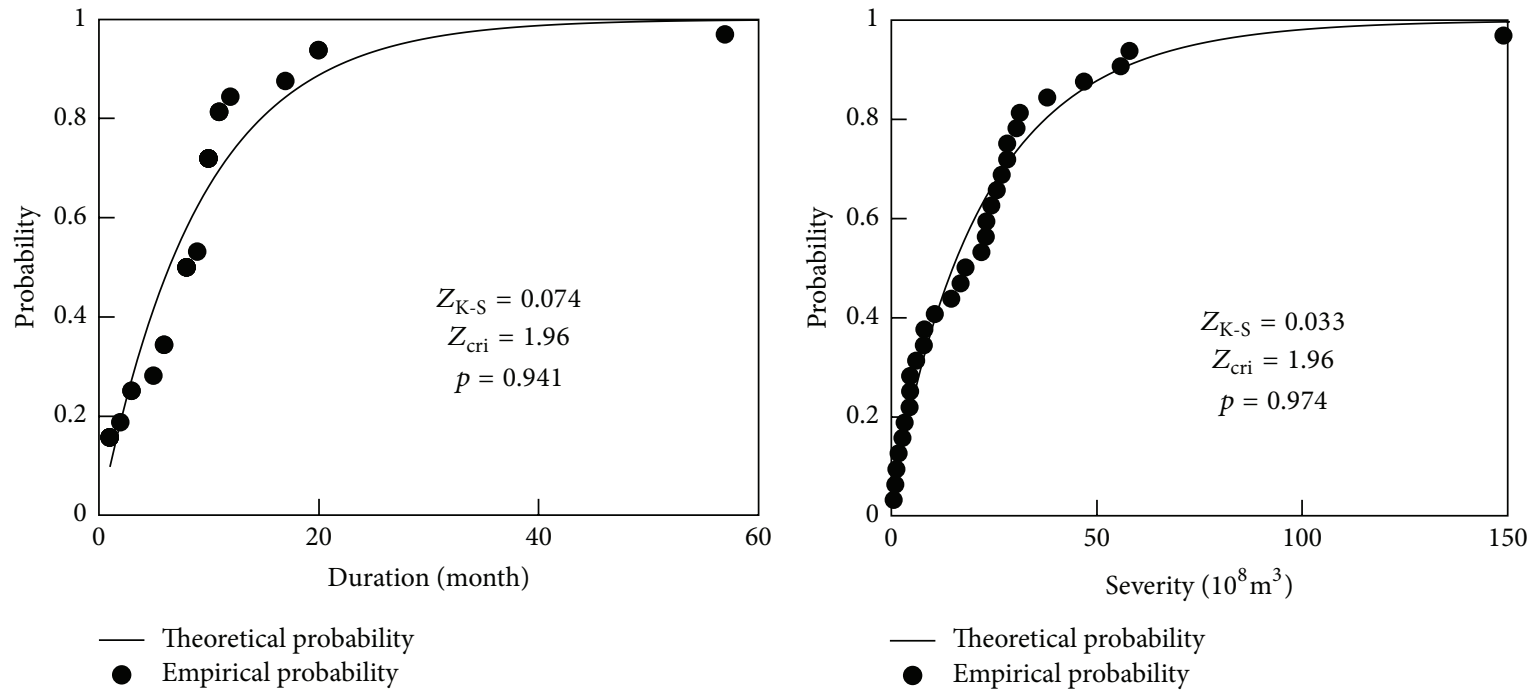

(c) A1B CSIRO

Figure 4: Continued. 

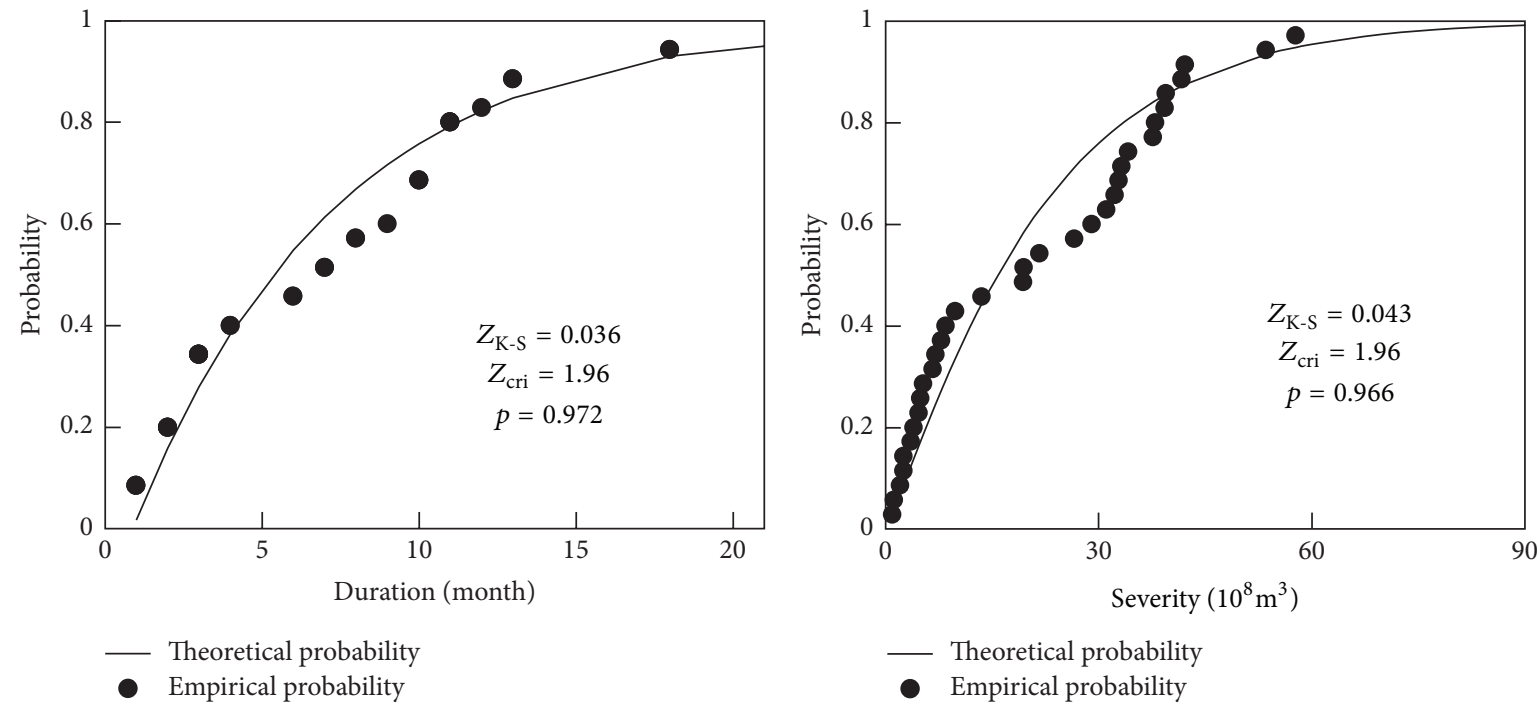

(d) AlB MPI

Figure 4: Theoretical distribution fitting for severity and duration under baseline and A1B scenarios with Z-score of two-sample KolmogorovSmirnov test statistics $\left(Z_{\mathrm{K}-\mathrm{S}}\right.$ is the calculated Z-score of the K-S test statistics and $Z_{\text {cri }}$ is the critical Z-score at a $5 \%$ significance level).

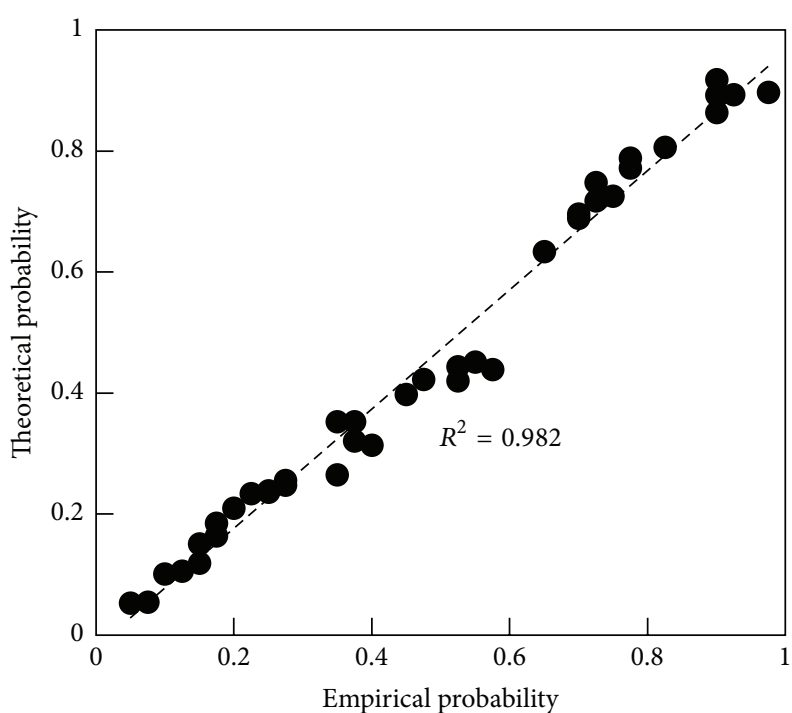

(a) Baseline

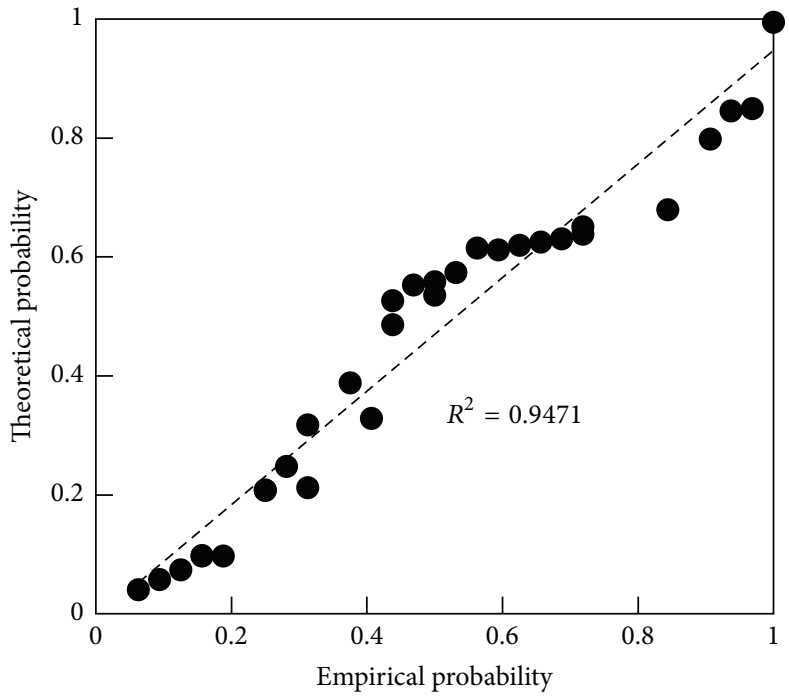

(c) AlB CSIRO

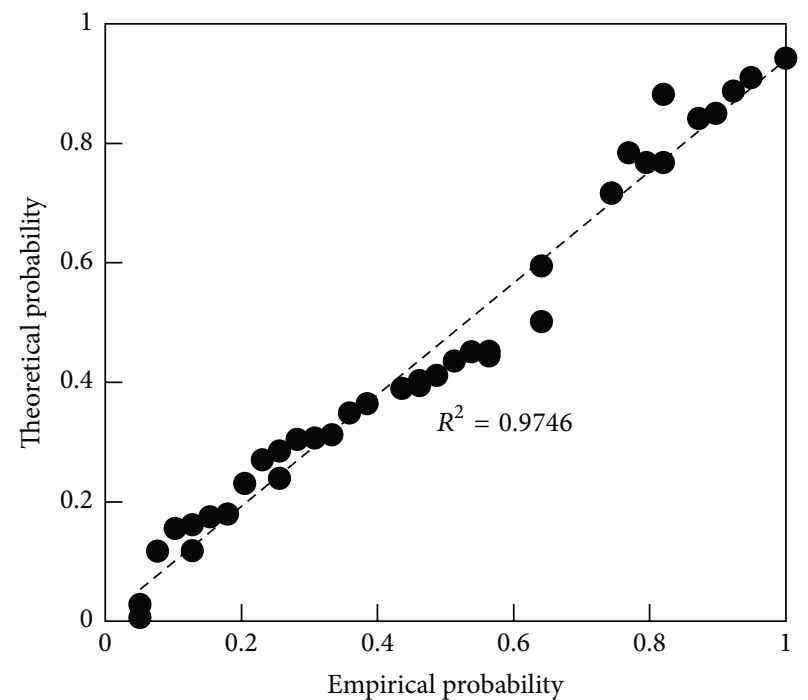

(b) AlB PRECIS

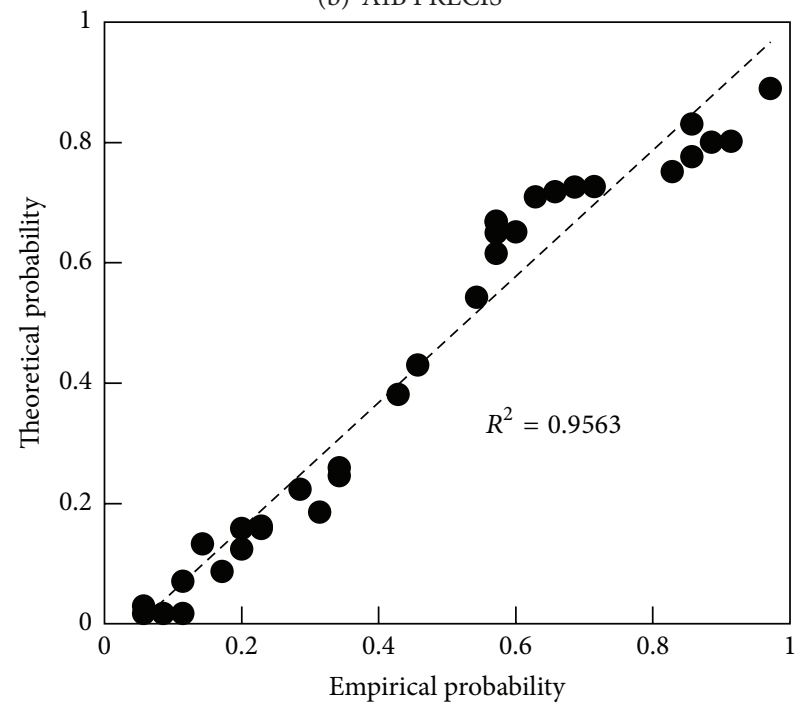

(d) AlB MPI

FIGURE 5: Empirical and theoretical joint probabilities of drought severity and duration under baseline and three A1B scenarios. 
TABLE 3: Validation of univariate/bivariate model-based droughts against historical severe and extreme drought records in the baseline period (1961-1990).

\begin{tabular}{|c|c|c|c|c|c|}
\hline \multirow{2}{*}{ Year } & \multicolumn{2}{|c|}{ Historical drought conditions } & \multirow{2}{*}{$\begin{array}{c}\text { Univariate model } \\
\text { (Severity) }\end{array}$} & \multirow{2}{*}{$\begin{array}{c}\text { Univariate model } \\
\text { (Duration) }\end{array}$} & \multirow{2}{*}{$\begin{array}{c}\text { Bivariate model } \\
\text { (Duration-severity) }\end{array}$} \\
\hline & Shaanxi & Gansu & & & \\
\hline 1962 & Severe & Extreme & $Y$ & $Y$ & $Y$ \\
\hline 1966 & Moderate & Severe & $Y$ & $Y$ & $N$ \\
\hline 1969 & Mild & Severe & $Y$ & $Y$ & $Y$ \\
\hline 1971 & Moderate & Extreme & $Y$ & $Y$ & $Y$ \\
\hline 1972 & Severe & Extreme & $Y$ & $Y$ & $Y$ \\
\hline 1973 & Mild & Extreme & $Y$ & $Y$ & $Y$ \\
\hline 1979 & Mild & Severe & $N$ & $Y$ & $N$ \\
\hline 1980 & Severe & Moderate & $Y$ & $Y$ & $Y$ \\
\hline 1981 & Moderate & Extreme & $Y$ & $Y$ & $Y$ \\
\hline 1982 & Moderate & Extreme & $Y$ & $Y$ & $Y$ \\
\hline 1986 & Severe & Moderate & $Y$ & $Y$ & $Y$ \\
\hline 1987 & Severe & Extreme & $Y$ & $Y$ & $Y$ \\
\hline
\end{tabular}

Note: symbol " $Y$ " indicates that the univariate or bivariate drought model is able to effectively identify the historical severe or extreme drought years in Shaanxi or Gansu province; and symbol " $N$ " denotes that the drought model fails to identify the historical drought records in Shaanxi or Gansu.

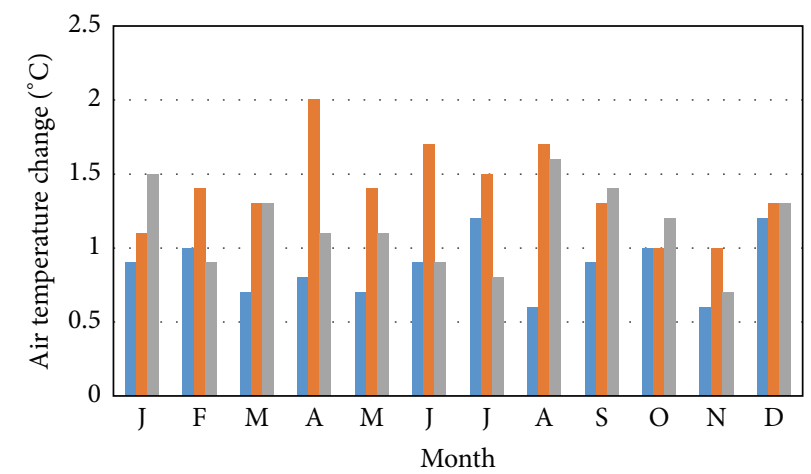

- A1B PRECIS

- A1B CSIRO

- A1B MPI

(a) Air temperature change

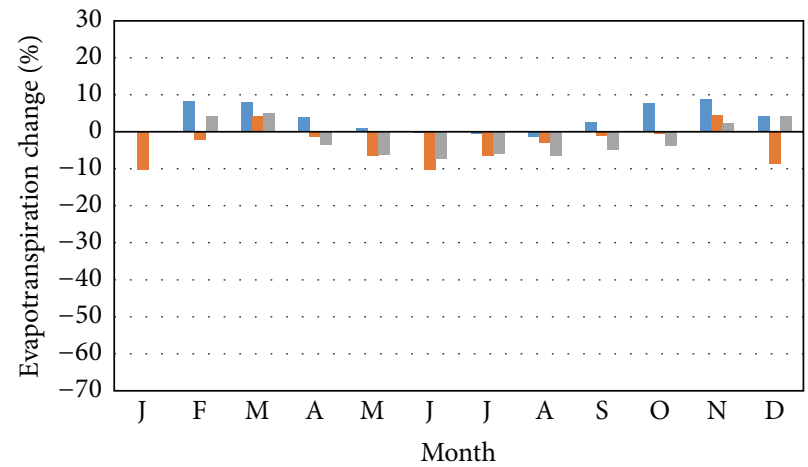

- A1B PRECIS

- A1B CSIRO

- A1B MPI

(c) Evapotranspiration change

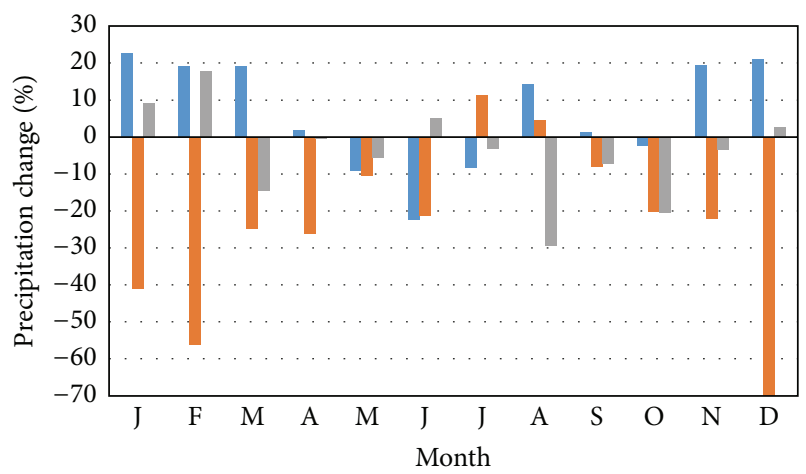

- A1B PRECIS

- A1B CSIRO

- A1B MPI

(b) Precipitation change

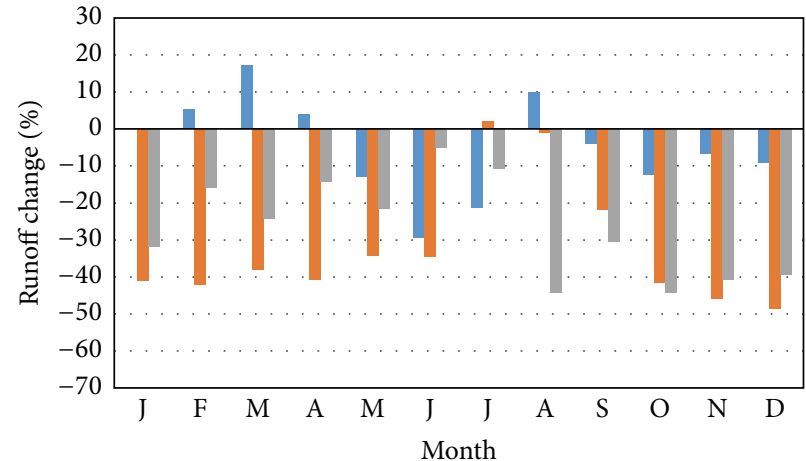

- A1B PRECIS

- A1B CSIRO

A1B MPI

(d) Runoff change

FIGURE 6: Projected changes in precipitation, air temperature, evapotranspiration, and runoff under AlB scenarios relative to baseline period. 


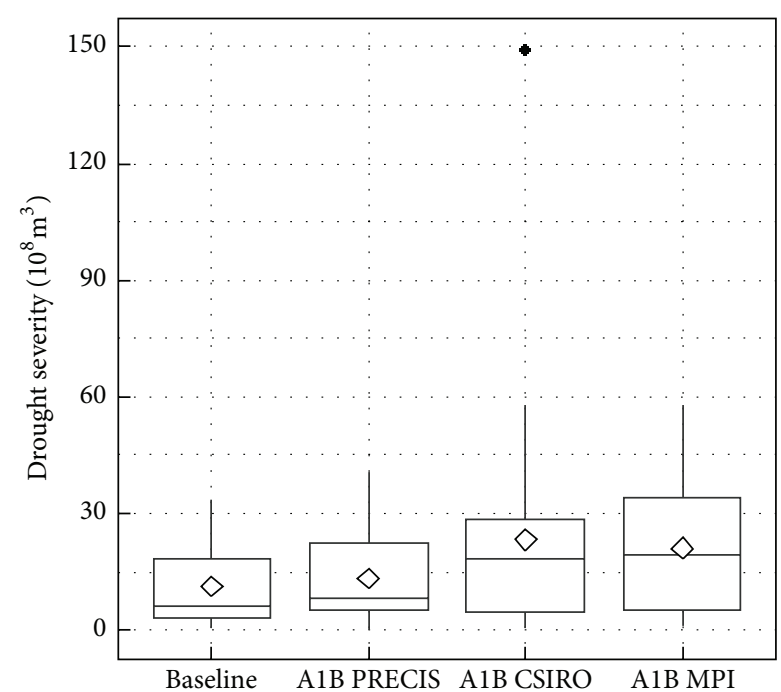

(a) Severity

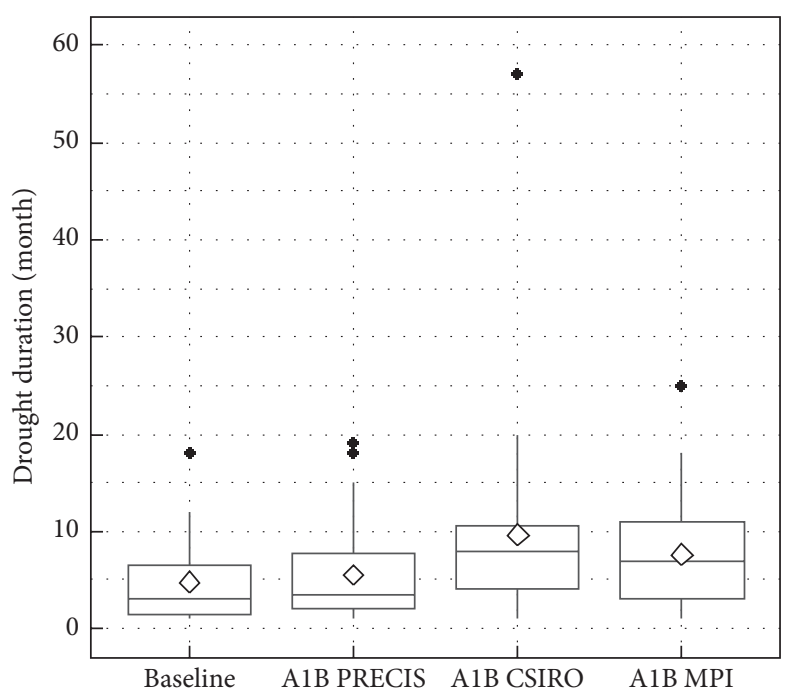

(b) Duration

FIgURE 7: Boxplots for drought severity and duration samples under baseline and A1B scenarios (the diamond symbol indicates the means of drought severity or duration).

for AlB PRECIS, $1.0 \sim 2.0^{\circ} \mathrm{C}$ for AlB CSIRO, and $0.7 \sim 1.6^{\circ} \mathrm{C}$ for A1B MPI. PRECIS projects no distinct changes in mean annual precipitation under A1B scenario, with a minor drop of $1.4 \mathrm{~mm}$ relative to the baseline level $(559.3 \mathrm{~mm})$, while the CSIRO and MPI GCMs simulate a considerable reduction of $47.9 \mathrm{~mm}(8.6 \%)$ and $51.1 \mathrm{~mm}(9.1 \%)$ in mean annual precipitation under A1B. Meanwhile, all the three CMs project obvious changes in seasonal precipitation. As shown in Figure 6(b), precipitation would generally undergo a substantial decrease in most months. However, PRECIS projects a significant precipitation increase in August and November-March; CSIRO simulates a considerable remarkable rise of precipitation in July and August; MPI projects an obvious increase in precipitation in January and February.

Driven by the baseline and three future climate data sets, the VIC model was used to simulate and project hydrological processes under baseline and A1B scenarios. Although the obvious increase in air temperature potentially promotes the atmospheric demand for evapotranspiration, actual evapotranspiration would undergo a slight reduction almost throughout the year under A1B CSIRO and A1B MPI (Figure 6(c)). This is attributed to the phenomenon that both CSIRO and MPI project a considerable precipitation decrease in most months which is very likely to restrict the water supply for evapotranspiration. Using the A1B PRECIS climate data set as inputs, the VIC model projects a minor increase in evapotranspiration in spring and autumn and a slight decrease in summer. As shown in Figure 6(d), runoff would drop significantly in most months. Under AlB PRECIS, a substantial runoff increase would occur in February-April and August, mainly due to the projected remarkable precipitation rise in the same period. It is notable that although all the CMs generally project the WRB towards a drying trend in the future, the different magnitudes of air temperature and precipitation changes from different CMs are likely to lead to large uncertainties in the projected future runoff. This uncertainty may further largely impact the projections of hydrological drought events under future scenarios.

4.4. Projected Climate Change Impact on Hydrological Droughts. The simulated monthly streamflow at Huaxian station was used to derive the drought characteristics under baseline and A1B scenarios, and the identified properties of hydrological drought events were employed for univariate and copula-based bivariate drought analysis.

4.4.1. Univariate Drought Analysis. According to the theory of runs, 39 hydrological drought events were identified for the baseline period, together with 38, 31, and 34 events under A1B PRECIS, A1B CSIRO, and A1B MPI scenarios, respectively. Relative to the baseline level, fewer hydrological drought events would occur under A1B. However, the means and medians of drought variables under all three future scenarios are projected to increase considerably. Figure 7 shows that the mean drought severity and duration are $11.2 \times 10^{8} \mathrm{~m}^{3}$ and 4.8 months for the baseline period, while the values of these drought variables would increase to be $12.9 \times 10^{8} \mathrm{~m}^{3}$ and 5.5 months for A1B PRECIS, $18.5 \times 10^{8} \mathrm{~m}^{3}$ and 9.6 months for A1B CSIRO, and $18.3 \times 10^{8} \mathrm{~m}^{3}$ and 7.6 months for A1B MPI. Meanwhile, under A1B CSIRO and A1B MPI scenarios, much worse drought conditions are projected. In the baseline period, the most severe drought event was identified to be from November 1961 to April 1963, with the duration of 18 months and the severity of $29.8 \times 10^{8} \mathrm{~m}^{3}$. However, under A1B CSIRO, a long-term extreme drought is projected from October 2020 to June 2025, with the duration and severity being up to 57 months and $149.0 \times 10^{8} \mathrm{~m}^{3}$, respectively. 
TABLE 4: Drought characteristics in different univariate return periods under baseline and A1B scenarios.

\begin{tabular}{|c|c|c|c|c|c|c|c|c|}
\hline \multirow{2}{*}{ Return periods } & \multicolumn{4}{|c|}{ Drought severity $\left(10^{8} \mathrm{~m}^{3}\right)$} & \multicolumn{4}{|c|}{ Drought duration (month) } \\
\hline & Baseline & A1B PRECIS & A1B CSIRO & A1B MPI & Baseline & A1B PRECIS & A1B CSIRO & A1B MPI \\
\hline 50 years & 44.2 & 48.0 & 98.2 & 73.9 & 18.4 & 20.5 & 35.8 & 26.1 \\
\hline 20 years & 33.8 & 37.6 & 73.5 & 58.3 & 13.9 & 15.7 & 27.4 & 20.1 \\
\hline 10 years & 25.9 & 29.5 & 55.2 & 46.1 & 10.7 & 12.0 & 21.1 & 15.7 \\
\hline 5 years & 18.1 & 21.2 & 37.4 & 33.4 & 7.3 & 8.4 & 17.4 & 11.2 \\
\hline
\end{tabular}

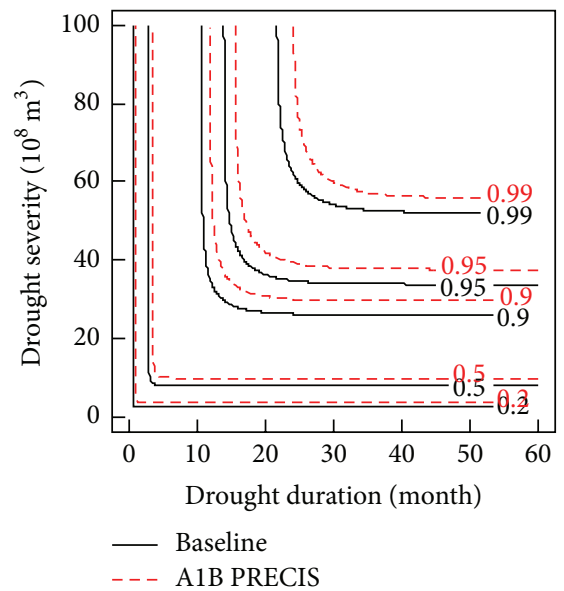

(a) Baseline VS A1B PRECIS

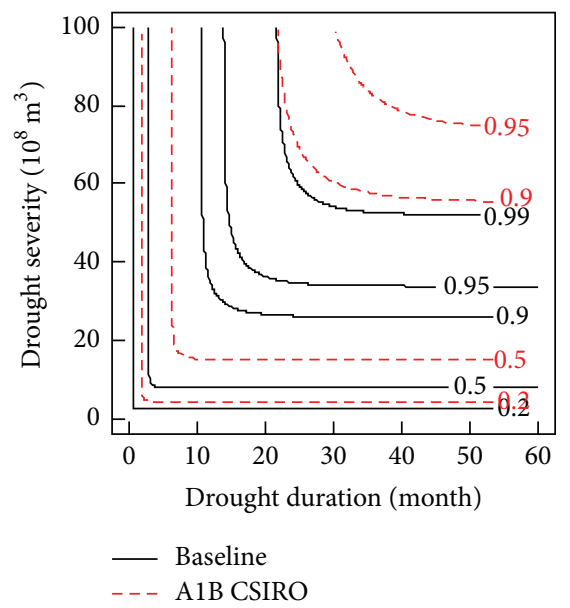

(b) Baseline VS A1B CSIRO

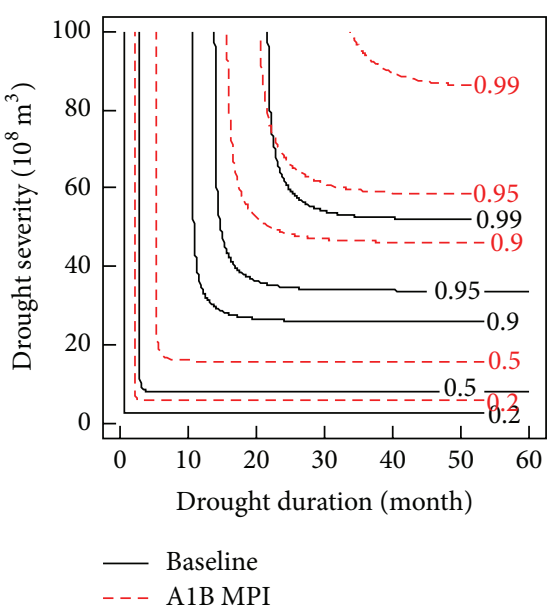

(c) Baseline VS A1B MPI

FIGURE 8: Bivariate joint probability of drought duration and severity under baseline and three A1B scenarios.

In the case of A1B MPI, the most extreme drought would occur from June 2023 to June 2025, with the duration of 25 months and the severity of $57.7 \times 10^{8} \mathrm{~m}^{3}$; and a comparable extreme drought event is also projected under A1B PRECIS.

The exponential and Weibull distributions were adopted to fit the drought duration and severity samples under three future scenarios, respectively. Figures 4(b)-4(d) illustrate that the identified drought duration and severity samples preferably follow the exponential and Weibull distributions. With the univariate drought probabilistic models, drought severity and duration referring to different return periods were estimated. Table 4 shows that drought severity and duration in all return periods would increase remarkably under all three A1B scenarios, especially with the dramatic rise in the cases of A1B CSIRO and A1B MPI. Compared with the baseline situation, the 50-year drought severity would increase by $122.2 \%$ and $67.2 \%$ under A1B CSIRO and A1B $\mathrm{MPI}$, and the 50 -year drought duration is projected to rise by 17.4 and 7.7 months, respectively. This univariate drought analysis implies that future climate change under A1B would deteriorate the drought situation in the WRB, especially with increased frequencies of extreme hydrological drought events with higher severities and longer durations. It should be noted that the drought simulations as short as 30 years for both baseline and A1B scenarios may not sufficiently capture the changes in drought events at higher return period levels (such as 50 years) and a larger sample size of drought duration and severity data sets for both scenarios are required so as to reduce this uncertainty. In general, driven by the three CM data sets, the VIC hydrological model and the univariate probabilistic drought models project similar deteriorated drought conditions in the WRB under all three A1B scenarios, but with different magnitudes of changes in drought severity and duration. This uncertainty in drought projections might mainly result from the possible large uncertainties in climate data sets from different climate models.

4.4.2. Bivariate Drought Analysis. To derive the joint distributions of drought severity and duration under three A1B scenarios, four copula functions were adopted. Table 2 and Figures 5(b)-5(d) show that the Clayton copula is able to effectively characterize the joint duration-severity distributions under all A1B scenarios. To quantify possible future climate change impacts on drought conditions, the joint probability, conditional probability, and joint return period under all future scenarios were compared with those of the baseline period.

Figure 8 shows the contours of joint probability for drought duration and severity under baseline and future scenarios. It demonstrates that large distance exists between the contours for baseline and $\mathrm{AlB}$ drought events at the same probability levels. On the basis of those contours, if the same duration or severity is given for both baseline and future events, the corresponding severity or duration values under all A1B scenarios are found to be considerably larger than those of baseline drought events. In consequence, 


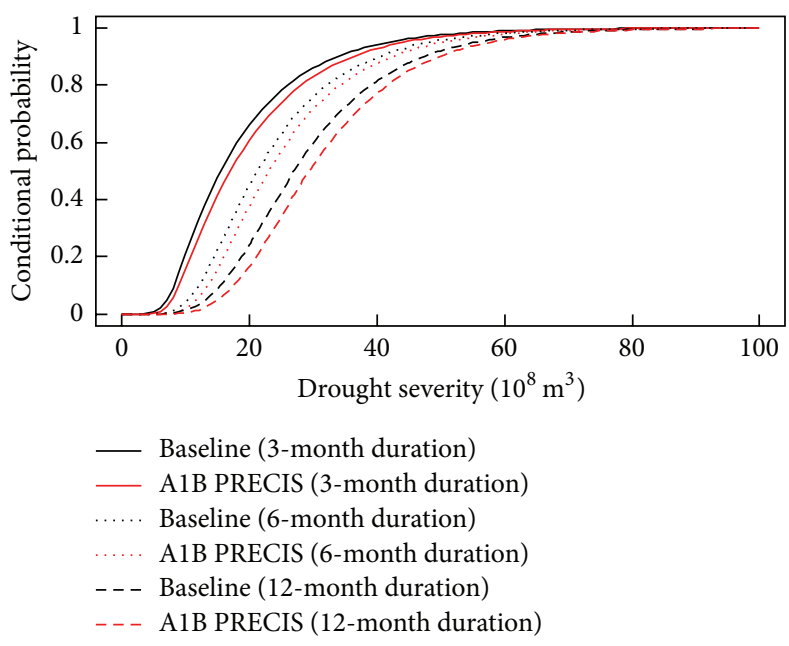

(a) Baseline VS A1B PRECIS

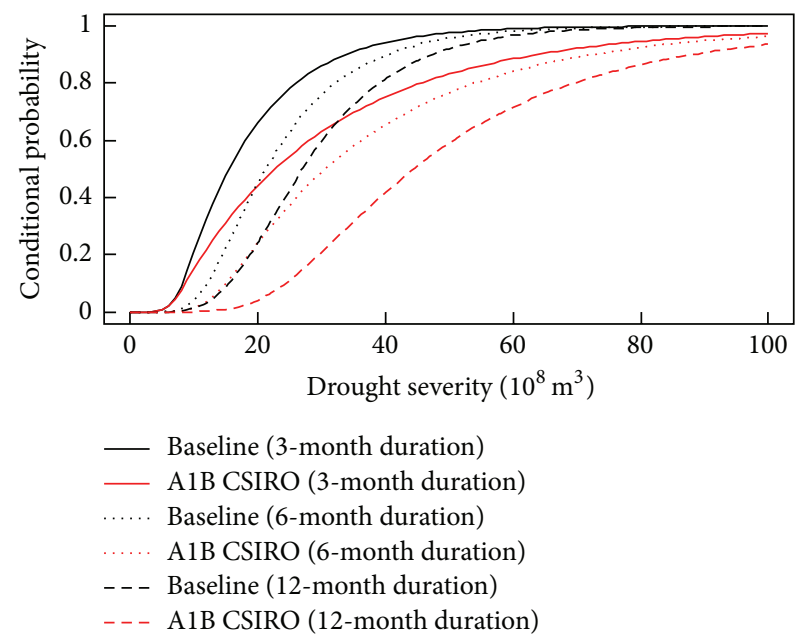

(b) Baseline VS A1B CSIRO

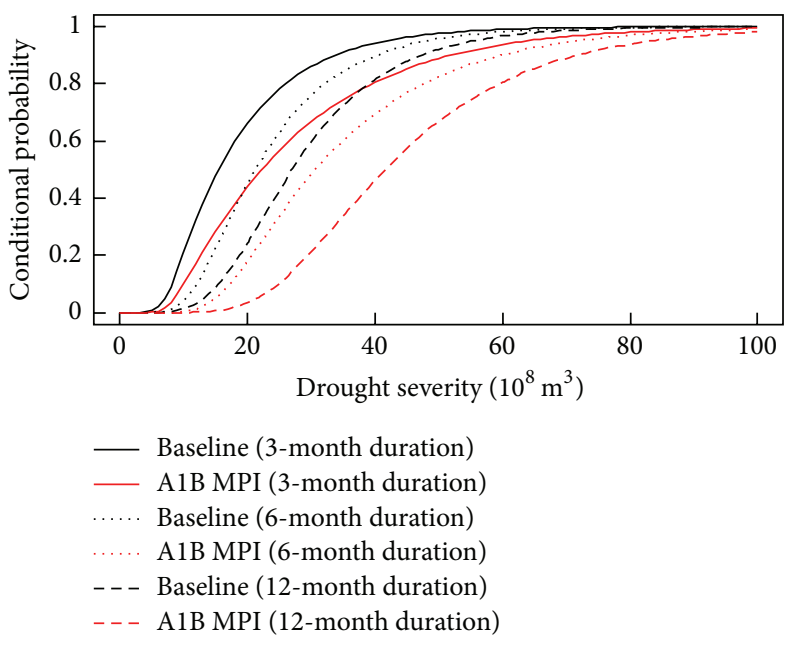

(c) Baseline VS A1B MPI

FIGURE 9: Conditional probability of drought severity distributions with given durations of 3, 6, and 12 months under baseline and three A1B scenarios.

more severe drought conditions are projected under three A1B scenarios, and the basin would experience the most serious hydrological drought situations under A1B CISRO and A1B MPI. This phenomenon can also be illustrated by the conditional distributions of drought severities given certain durations (Figure 9). For example, given a 6-month duration, the conditional probability of baseline drought events with severity less than or equal to $30.0 \times 10^{8} \mathrm{~m}^{3}$ is approximately 0.758 (Figure 9(a)). However, the same probability corresponds to the A1B PRECIS drought event with severity less than or equal to $33.1 \times 10^{8} \mathrm{~m}^{3}$ (Figure 9(a)), and such a probability is also in correspondence with the A1B CSIRO and A1B MPI drought events with severity less than or equal to $50.2 \times 10^{8} \mathrm{~m}^{3}$ (Figure $9(\mathrm{~b})$ ) and $45.4 \times 10^{8} \mathrm{~m}^{3}$ (Figure $9(\mathrm{c})$ ), respectively.

Figure 10 shows the contour plots of joint severity-duration return periods of $T_{\mathrm{DS}}^{\mathrm{AND}}$ and $T_{\mathrm{DS}}^{\mathrm{OR}}$ under baseline and three $\mathrm{A} 1 \mathrm{~B}$ scenarios. In comparison with the baseline situation, more serious drying conditions under the three A1B scenarios are projected in terms of the calculated joint return periods. For instance, the drought event with a 10-month duration and a $40.0 \times 10^{8} \mathrm{~m}^{3}$ severity leads to $T_{\mathrm{DS}}^{\mathrm{AND}}$ of 41.3 years and $T_{\mathrm{DS}}^{\mathrm{OR}}$ of 6.1 years in the baseline period. However, if the same drought event occurred under A1B PRECIS, such bivariate return periods would reduce to be 27.1 years and 5.0 years, respectively; $T_{\mathrm{DS}}^{\mathrm{AND}}$ and $T_{\mathrm{DS}}^{\mathrm{OR}}$ would further drop to be 7.7 years and 3.3 years under A1B MPI and to be 5.7 years and 2.8 years under A1B CSIRO.

\section{Conclusions and Discussion}

In this study, a modeling system for projecting the potential future climate change impacts on hydrological drought events in the WRB in North China is presented. This modeling system includes the VIC hydrological model driven by climate outputs from PRECIS RCM, CSIRO GCM, and MPI GCM for future streamflow projections, a univariate probabilistic model for drought severity and duration assessment, and a 

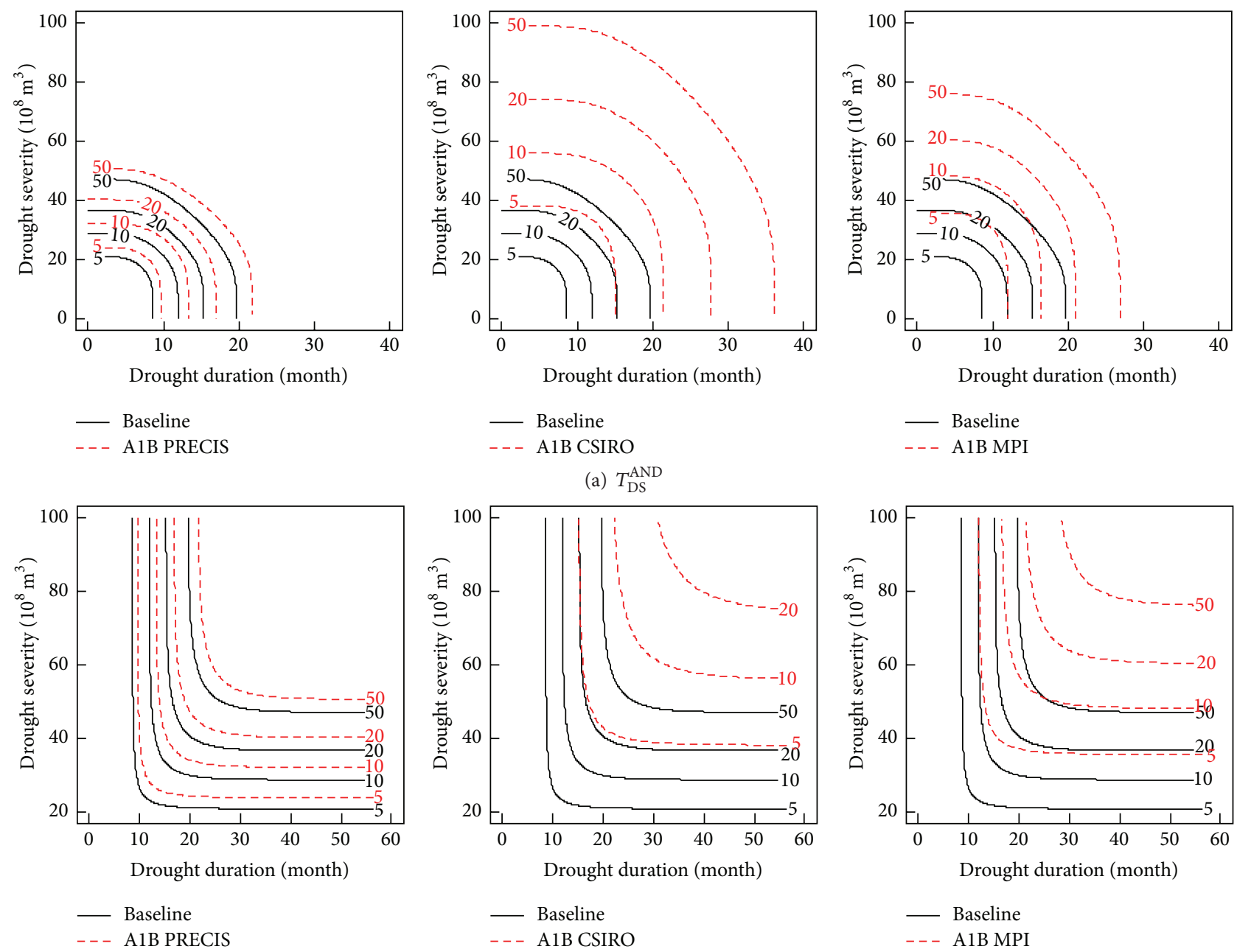

(b) $T_{\mathrm{DS}}^{\mathrm{OR}}$

FIGURE 10: Bivariate joint return periods of drought duration and severity under baseline and A1B scenarios: (a) $T_{\mathrm{DS}}^{\mathrm{AND}}$ defined by (7) and (b) $T_{\mathrm{DS}}^{\mathrm{OR}}$ defined by (8).

copula-based model for bivariate drought assessment and joint frequency analysis under historical and future climates. Driven by the observed climate data, the modeling system is able to effectively identify most historical severe and extreme severe droughts in the WRB. The VIC model fed with three $\mathrm{CM}$ data sets, in general, projected a considerable runoff reduction under IPCC-SRES A1B scenario. This further triggers much worse drought conditions in the future. It is found in the univariate drought assessment that although fewer hydrological drought events would occur under A1B scenario, such drought variables as duration and severity were projected to increase considerably. The bivariate drought assessment using copula reveals that if historical droughts at a certain return period reoccurred under the future scenarios, the corresponding joint return periods would decrease remarkably. With these trends in the future, the hydrological drought situation in the WRB would be further deteriorated, and effective water saving techniques and rational water resources management strategies should be carried out for drought disaster mitigations.
It should be noted that, with the projected streamflow at Huaxian station being adopted for univariate and bivariate drought assessments, only the general drought conditions in the upstream area controlled by Huaxian hydrological station were projected in this study. To consider the spatiotemporal variations of drought conditions in the WRB, future work will be carried out to analyze the VIC-calculated runoff depth at each grid cell within the study area with the similar methodology in this study.

It is interesting to notice that although all modeling runs with different CM data sets consistently project future droughts to be deteriorated in the $\mathrm{WRB}$, the projected drought conditions under A1B CSIRO and A1B MPI tend to be more serious than the case of A1B PRECIS. Several studies [30-32] found that CMs are the dominant uncertainty source, influencing future streamflow projections. Given that the VIC model is able to accurately reproduce the historical monthly streamflow at Huaxian station (Table 1 and Figure 3 ), the uncertainties of streamflow from CMs are very likely to predominantly further affect future hydrological drought 
projections in this study. Consequently the uncertainty in drought projections might mainly originate from the uncertainties of CMs. Therefore, it is necessary to quantitatively evaluate the effects of the CM uncertainties on future drought projections. Furthermore, the PRECIS and CSIRO climate data sets under the IPCC-SRES B1 scenario were also adopted for future drought projections in this study (the results are not shown in this paper). It shows that the WRB would experience deteriorated drought conditions under $\mathrm{B} 1$, but the drying magnitude is less severe than that under A1B. This implies that the uncertainty from the adopted emission scenarios is nonignorable as well, which should be quantified in future studies. In addition, currently the new projected future climate data sets from the Coupled Model Intercomparison Project phase 5 (CMIP5) are available, which employed the latest generation of GCMs under the scenarios of Representative Concentration Pathways (RCPs) [33]. Therefore, it is encouraged to use this latest climate projection product for drought projections in future studies.

\section{Conflict of Interests}

The authors declare that there is no conflict of interests regarding the publication of this paper.

\section{Acknowledgments}

This study is sponsored by the National Key Technology R\&D Program of Ministry of Sciences and Technology, China (Grant no. 2013BAC10B02), the Special Fund of State Key Laboratory of Hydrology-Water Resources and Hydraulic Engineering (Grant no. 20145031112), and the National Natural Science Foundation of China (Grant no. 41323001).

\section{References}

[1] M. Ma, L. Ren, V. P. Singh, X. Tu, S. Jiang, and Y. Liu, "Evaluation and application of the SPDI-JDI for droughts in Texas, USA," Journal of Hydrology, vol. 521, pp. 34-45, 2015.

[2] G. Yan, Z. Wu, and D. Li, "Comprehensive analysis of the persistent drought events in Southwest China," Disaster Advances, vol. 6, no. 3, pp. 306-315, 2013.

[3] F. K. Yu, X. H. Huang, Q. B. Liang et al., "Ecological water demand of regional vegetation: the example of the 2010 severe drought in Southwest China," Plant Biosystems, vol. 149, no. 1, pp. 100-110, 2015.

[4] G. Fu, S. Chen, C. Liu, and D. Shepard, "Hydro-climatic trends of the yellow river basin for the last 50 years," Climatic Change, vol. 65, no. 1-2, pp. 149-178, 2004.

[5] M. Ma, S. Song, L. Ren, S. Jiang, and J. Song, "Multivariate drought characteristics using trivariate Gaussian and student t copulas," Hydrological Processes, vol. 27, no. 8, pp. 1175-1190, 2013.

[6] B. Zhang, P. Wu, X. Zhao, Y. Wang, X. Gao, and X. Cao, "A drought hazard assessment index based on the VIC-PDSI model and its application on the Loess Plateau, China," Theoretical and Applied Climatology, vol. 114, no. 1-2, pp. 125-138, 2013.

[7] J.-T. Shiau, S. Feng, and S. Nadarajah, "Assessment of hydrological droughts for the Yellow River, China, using copulas," Hydrological Processes, vol. 21, no. 16, pp. 2157-2163, 2007.
[8] S. Song and V. P. Singh, "Frequency analysis of droughts using the Plackett copula and parameter estimation by genetic algorithm," Stochastic Environmental Research and Risk Assessment, vol. 24, no. 5, pp. 783-805, 2010.

[9] L. Cheng, Z. Xu, and Z. Liu, "Hydrological response to climate change in the weihe river basin," in Proceedings of the 4th International Yellow River Forum on Ecological Civilization and River Ethics, vol. 1, pp. 221-230, 2010.

[10] Q. Huang and J. Fan, "Detecting runoff variation of the mainstream in Weihe river," Journal of Applied Mathematics, vol. 2013, Article ID 356474, 8 pages, 2013.

[11] J. Du and C.-X. Shi, "Effects of climatic factors and human activities on runoff of the Weihe River in recent decades," Quaternary International, vol. 282, pp. 58-65, 2012.

[12] Y. Guo, Z. Li, M. Amo-Boateng, P. Deng, and P. Huang, "Quantitative assessment of the impact of climate variability and human activities on runoff changes for the upper reaches of Weihe River," Stochastic Environmental Research and Risk Assessment, vol. 28, no. 2, pp. 333-346, 2014.

[13] S. Madadgar and H. Moradkhani, "Drought analysis under climate change using copula," Journal of Hydrologic Engineering, vol. 18, no. 7, pp. 746-759, 2013.

[14] J. Liu, W. Kuang, Z. Zhang et al., "Spatiotemporal characteristics, patterns, and causes of land-use changes in China since the late 1980s," Journal of Geographical Sciences, vol. 24, no. 2, pp. 195-210, 2014.

[15] IPCC, Climate Change 2001: The Scientific Basis, Contribution of Working Group I to the Third Assessment Report of the Intergovernmental Panel on Climate Change, Cambridge University Press, Cambridge, UK, 2001.

[16] W. Chen, Z. Jiang, and L. Li, "Probabilistic projections of climate change over China under the SRES A1B scenario using 28 AOGCMs," Journal of Climate, vol. 24, no. 17, pp. 4741-4756, 2011.

[17] Y.-L. Song, D.-L. Chen, Y.-J. Liu, and Y. Xu, "The influence of climate change on winter wheat during 2012-2100 under A2 and A1B scenarios in China," Advances in Climate Change Research, vol. 3, no. 3, pp. 138-146, 2012.

[18] X. Liang, E. F. Wood, D. P. Lettenmaier, and S. J. Burges, "A simple hydrologically based model of land surface water and energy fluxes for general circulation models," Journal of Geophysical Research, vol. 99, no. 7, pp. 14415-14428, 1994.

[19] X. Liang, D. P. Lettenmaier, E. F. Wood, and S. J. Burges, “Onedimensional statistical dynamic representation of subgrid spatial variability of precipitation in the two-layer variable infiltration capacity model," Journal of Geophysical Research D: Atmospheres, vol. 101, no. 16, pp. 21403-21422, 1996.

[20] J. A. Cunge, "On the subject of a flood propagation computation method (Musklngum Method)," Journal of Hydraulic Research, vol. 7, no. 2, pp. 205-230, 1969.

[21] W. J. Rawls, L. R. Ahuja, D. L. Brakensiek, and A. Shirmohammadi, "Infiltration and soil water movement," in Handbook of Hydrology, D. R. Maidment, Ed., pp. 5.1-5.51, McGraw-Hill, New York, NY, USA, 1993.

[22] B. J. Cosby, G. M. Hornberger, R. B. Glapp, and T. R. Ginn, "A statistical exploration of the relationships of soil moisture characteristics to the physical properties of soils," Water Resources Research, vol. 20, no. 6, pp. 682-690, 1984.

[23] Z. Xie, F. Yuan, Q. Duan, J. Zheng, M. Liang, and F. Chen, "Regional parameter estimation of the VIC land surface model: methodology and application to river basins in China," Journal of Hydrometeorology, vol. 8, no. 3, pp. 447-468, 2007. 
[24] Q. Duan, S. Sorooshian, and V. K. Gupta, "Optimal use of the SCE-UA global optimization method for calibrating watershed models," Journal of Hydrology, vol. 158, no. 3-4, pp. 265-284, 1994.

[25] A. K. Fleig, L. M. Tallaksen, H. Hisdal, and S. Demuth, "A global evaluation of streamflow drought characteristics," Hydrology and Earth System Sciences, vol. 10, no. 4, pp. 535-552, 2006.

[26] Ministry of Water Resources of the People's Republic of China, Standard for Information and Hydrological Forecasting (GB/T 22482-2008), China Standard Press, Beijing, China, 2008.

[27] K. Sklar, "Fonctions de reparitition å n dimensions et leura marges," Publications de l'Institut de statistique de l'Université de Paris, vol. 8, pp. 229-231, 1959.

[28] R. B. Nelsen, An Introduction to Copulas, Springer, New York, NY, USA, 2006.

[29] S. Zhang, Y. Su, D. Song et al., The Historical Droughts in China: 1949-2000, Hohai University Press, Nanjing, China, 2008 (Chinese).

[30] T. Bosshard, M. Carambia, K. Goergen et al., "Quantifying uncertainty sources in an ensemble of hydrological climateimpact projections," Water Resources Research, vol. 49, no. 3, pp. 1523-1536, 2013.

[31] C. Dobler, S. Hagemann, R. L. Wilby, and J. Stötter, "Quantifying different sources of uncertainty in hydrological projections in an Alpine watershed," Hydrology and Earth System Sciences, vol. 16, no. 11, pp. 4343-4360, 2012.

[32] C. Prudhomme and H. Davies, "Assessing uncertainties in climate change impact analyses on the river flow regimes in the UK. Part 2: future climate," Climatic Change, vol. 93, no. 1-2, pp. 197-222, 2009.

[33] K. E. Taylor, R. J. Stouffer, and G. A. Meehl, "An overview of CMIP5 and the experiment design," Bulletin of the American Meteorological Society, vol. 93, no. 4, pp. 485-498, 2012. 

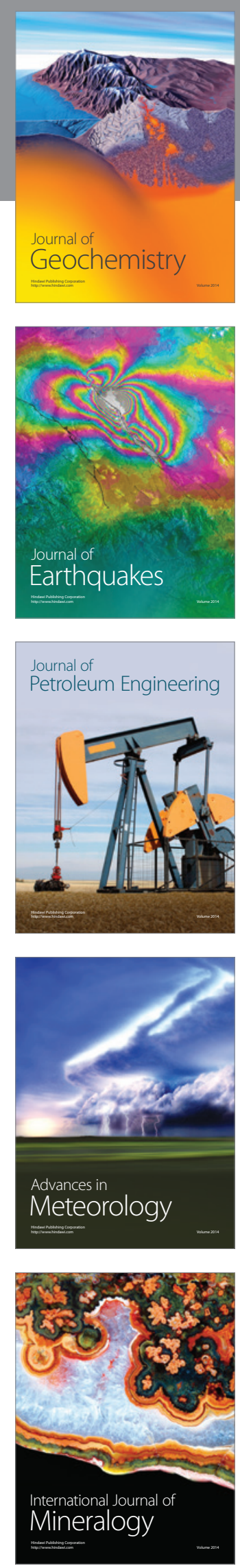
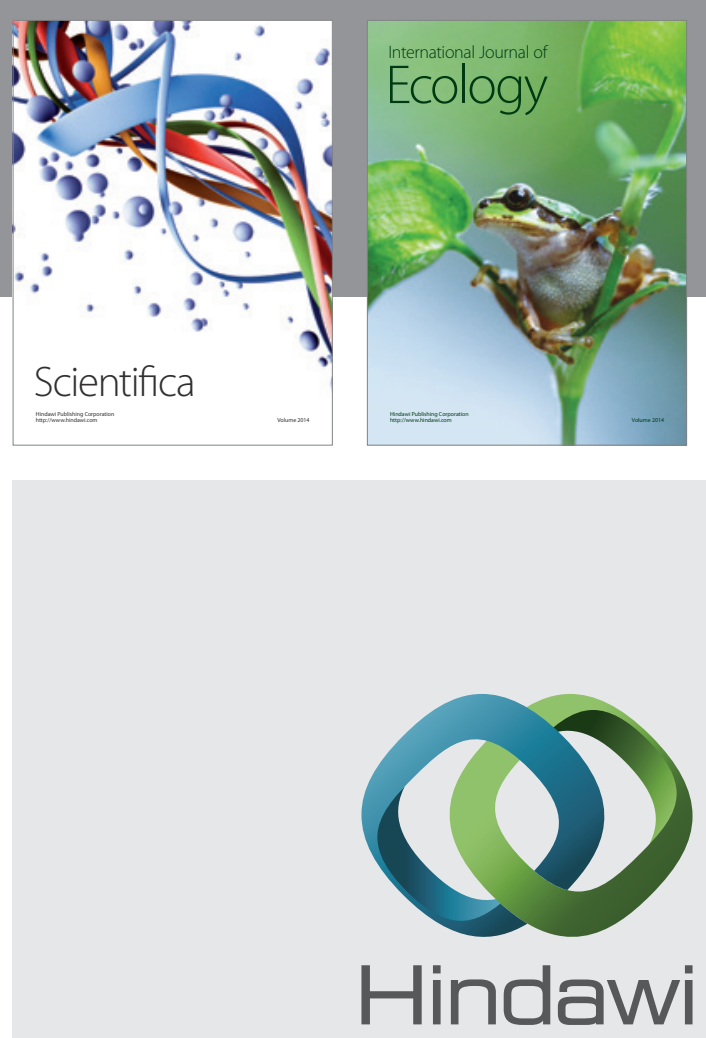

Submit your manuscripts at

http://www.hindawi.com
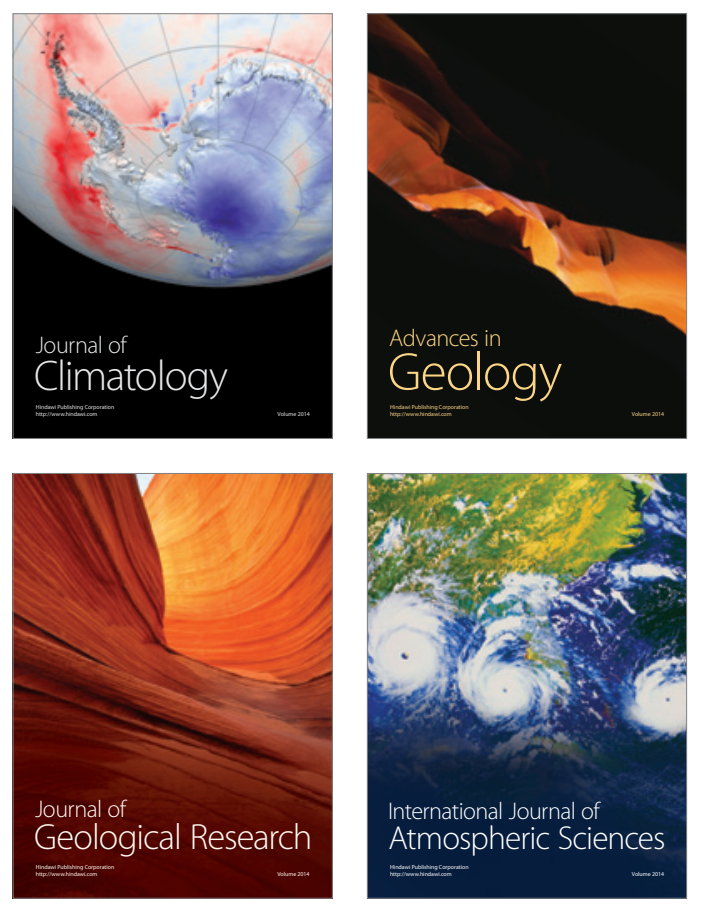

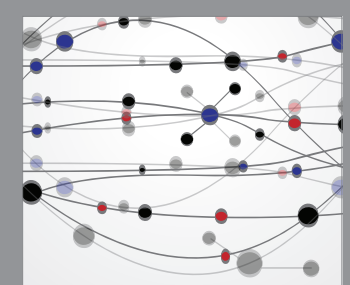

The Scientific

\section{World Journal}
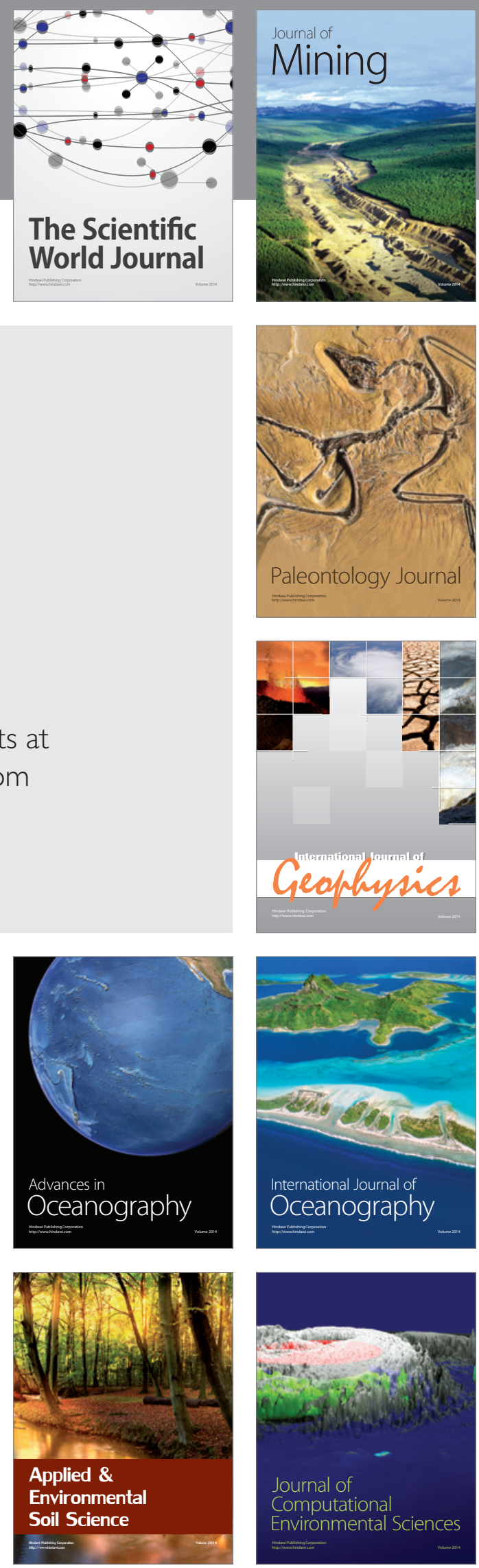